\title{
INFLUENZA IN RELATION TO THE CITY OF BIRMINGHAM
}

\author{
W. Nicol, M.B., CH.B., D.P.H. \\ Deputy Medical Officer of Health, Birmingham
}

IT seems reasonable in the first instance to examine how influenza in Birmingham has fitted into the general picture of the country as a whole in the past, particularly during the pandemic years of 1889 to 1894 and 1918 to 1919 and afterwards in more recent times.

In the latter part of the Igth century more than a generation had passed without the appearance of epidemic influenza in this country. With the early winter of 1889 , however, the newspapers began to make reference to it and long telegrams were received giving details of influenza in Moscow, St. Petersburg, Berlin, Paris, Madrid and other foreign capitals, but the following excerpts from the Report on the Pandemic of Influenza, 1918-19, seem adequately to indicate the general state of unpreparedness of the medical profession in the country at that time for it:

'Yet it has to be plainly stated and fully grasped by the reader that the recorded history of an epoch which, as we know, came to a definite end in December I889 in no way prepared us for subsequent events'.

And again:

'Little in written history can be brought forward as foreboding an impending change in the years immediately before 1890'.

This state was present equally in this city because in reviewing the old reports of the medical officers of health I find no reference made to influenza in 1889 , in fact the medical officer of health was more concerned about an epidemic of scarlet fever which had lasted about 14 years and was then coming to an end, and about an extraordinary number of deaths caused by diarrhœa and dysentery. He refers, however, in 1890 to a rise in the death rate which, in fact, was the highest for over 12 years, and the records show a marked rise in the incidence of deaths from bronchitis and pneumonia; but it was not until I89I that specific reference was made to influenza when 214 deaths were attributed to it. Of these, 204 occurred in the second quarter, $\vec{\omega}$ the disease first appearing in the mortality returns for $\stackrel{\sigma}{\sigma}$ the week ending May 2, when one death was registered. With the influenza came an abnormal mortality from bronchitis and pneumonia. In the second quarterthe quarter to which the epidemic of influenza was 6 practically confined-the deaths from bronchitis numbered 527 , and those from pneumonia 360 . These figures exceeded the averages for the five preceding spring quarters by 284 and 218 . This excessive fatality of chest affections cannot all be ascribed to climatic conditions, and it seems probable that a large proportion of it was really caused by influenza.

In Table $I$ the incidence of mortality at various ages is given.

It will be seen that it was among persons of 28 years of age and upwards that influenza was se terribly fatal; in those who had not reached adulf age the mortality was slight. To a less degreebut still very noticeably, the same was true of bronchitis and pneumonia. Thus in persons under 20 years of age the mortality from bronchitis was about $60 \%$ above the average; in persons above 20 years old $170 \%$ higher. In other words, the increase in the mortality from bronchitis was nearly three times as great in persons over 20 years old as in those under that age. In pneumonia the increase in persons under 20 years of age was over $90 \%$; in those aged 20 and upwards it was no less than $220 \%$. These figures show clearly that the incidence of influenza, and of the respiratory diseases affected by it, was most heavy amongst the adults.

TABLE I

\begin{tabular}{|c|c|c|c|c|c|c|c|}
\hline \multirow{3}{*}{ Ages } & & & lenza & & nchitis & & monia \\
\hline & & \multicolumn{6}{|c|}{ Spring Quarters of- } \\
\hline & & I891 & $\begin{array}{c}\text { Five Years, } \\
\text { 1 } 886-90\end{array}$ & I89I & $\begin{array}{c}\text { Five Years, } \\
\text { 1 } 886-90\end{array}$ & I89I & $\begin{array}{c}\text { Five Years, } \\
\text { 1886-90 }\end{array}$ \\
\hline $\begin{array}{l}\text { Under I year } \\
\text { I to } 5 \\
5 \text { to } 20 \\
20 \text { to } 40\end{array}$ & $\begin{array}{l}\ldots \\
\ldots \\
\ldots \\
\cdots \\
\cdots\end{array}$ & $\begin{array}{l}\text { I1 } \\
\text { I I } \\
10 \\
28 \\
78 \\
66\end{array}$ & $\begin{array}{l}- \\
z \\
-\end{array}$ & $\begin{array}{r}105 \\
77 \\
8 \\
14 \\
123 \\
200\end{array}$ & $\begin{array}{r}65 \\
48 \\
3 \\
9 \\
41 \\
77\end{array}$ & $\begin{array}{l}51 \\
74 \\
15 \\
68 \\
87 \\
65\end{array}$ & $\begin{array}{l}27 \\
36 \\
10 \\
23 \\
29 \\
17\end{array}$ \\
\hline All ages & .. & 204 & 一 & 527 & 243 & 360 & 142 \\
\hline
\end{tabular}


Deaths in 1891 were distributed in Birmingham as shown below:

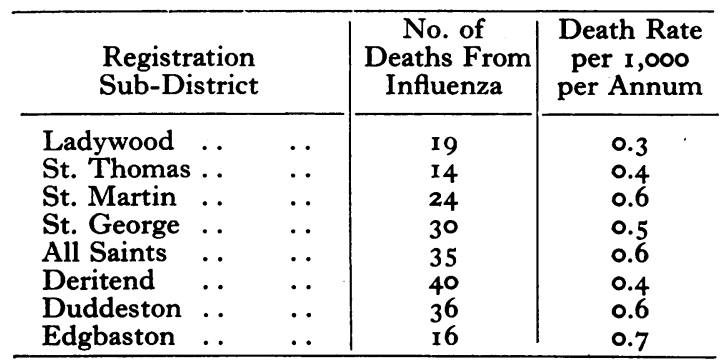

These figures show that Edgbaston had, proportionately to population, the greatest number of deaths primarily attributed to influenza. Of the other districts, St. Martin's, All Saints and Duddesdon suffered most. Better social conditions therefore did not mitigate the evil effects of the disease; it was as fatal among the upper as the lower classes of society of that day.

Although influenza was not recorded in the City until I89I, from the records of 1890 it seems to me that one might reasonably assume that influenza had, in fact, come rather earlier to the City, a fact that had not been realised by the Medical Officer of Health. This opinion is shared by Creighton (1894), who felt that this was undoubtedly so in the country as a whole.

It seems that the first wave was particularly mild, and this, together with lack of experience in the diagnosis of influenza, may explain why the first wave was apparently missed.

Total Deaths Attributed to Influenza, Bronchitis and PNeumonia in Birmingham DURING THE YeARS I890 TO I 893

\begin{tabular}{|c|c|c|c|c|c|}
\hline 1890 & $\cdots$ & $\cdots$ & $\cdots$ & 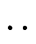 & 2,090 \\
\hline I 89I & . & $\cdot$ & . & $\ldots$ & 2,468 \\
\hline I 892 & $\cdots$ & $\cdots$ & . & $\cdots$ & $2,95^{\circ}$ \\
\hline 1893 & $\ldots$ & $\ldots$ & $\ldots$ & . & 2,250 \\
\hline
\end{tabular}

From the end of the igth century experience in Birmingham has been similar to that throughout the country as can be seen from Fig. $I$.

It is reported that the state of the public health in the country prior to 1890 in no way prepared them for the epidemic of 1890 and the incidence that occurred in the years to follow, but that the reverse was true, in the years which preceded 1918. From a study of local records this does not appear to be accurate as far as Birmingham was concerned. Certainly the years which preceded 1890 were far from satisfactory while those which immediately preceded 1918 were recorded in the words of the Medical Officer of Health as 'highly satisfactory' and, in fact, the Medical Officer of Health states in his foreword to his 1917 Annual Report that this was the healthiest year on record but: nevertheless,

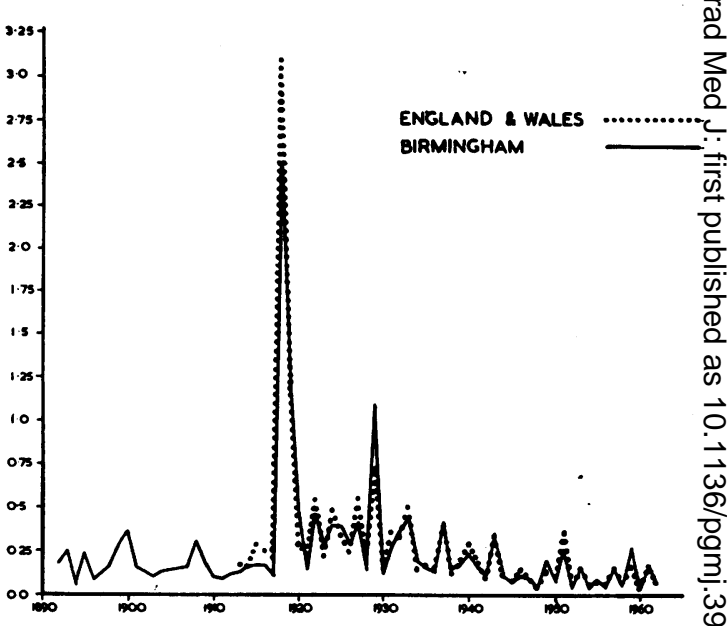

FIG. I.-Mortality from influenza 1892-1962. Rates per 1,000 population.

the experience of the rest of the country over the years 1918 to 1920 was shared by Birmingham.

The first epidemic commenced in the middle of $\frac{O}{0}$ June, 1918, and ended by the third week in July. For practical purposes it lasted six weeks. The weather was warm and dry. The feature whigh distinguished this epidemic from the following $t w 6$ was the extraordinary rapidity with which it spread over the whole City. The number of peoples attacked was larger than in the subsequent out- $\frac{\partial}{0}$ breaks, but the cases were in the majority of instances of a milder type. The onset was sudden, $\stackrel{\mathbb{Q}}{\mathscr{Q}}$ the prostration severe; however, in four or five $\overrightarrow{\vec{A}}$

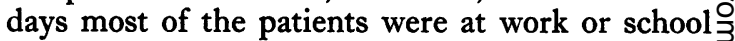
again. There was an interval of ten weeks with few (if any) new cases. Then between the firsto week in October and the last week in December the epidemic was one of great virulence, attacking 3 . many of those who had escaped during the July outbreak. The weather was cold, and for the most part dry. The symptoms were similar to those of the June cases, but more severe. Some patients died of influenza toxæmia in 24 to 48 음 hours. Many died of acute pneumonia, which, $>$ in the vast majority of cases, was a confluent broncho-pneumonia, with some purulent bron-ñ chitis. The Medical Officer of Health reports ${ }^{\circ}$ that there appeared to be some evidence that the $N$ attack in June protected against the attack in November but this was by no means absolute and he was of the opinion that a large part of the wholeco population escaped the disease although frequently $₫$ exposed to the infection.

The death rate attributable to influenza was evenly spread throughout the City, though the $\stackrel{\vec{D}}{\mathbb{D}}$ deaths attributed to pneumonia were more 
numerous in the centre than on the outskirts of the city.

As in the country as a whole Birmingham experienced four outbreaks - the first in June and July 1918, which was very extensive with a mortality of approximately 400 , but not so high as in subsequent outbreaks; the second in November and December 1918 was not so extensive but much more severe (about 2,000 deaths); the third in February and March 1919 was very severe but less extensive than the second ( 1,400 deaths); and the fourth in March and April 1920, which was a much slighter outbreak (about 400 deaths).

The distribution of the rate in wards of the City was somewhat different in the two years 1918 and 1919 as can be seen from the following excerpt from the 1919 Annual Report:

Death Rates From Influenza and Pneumonia

\begin{tabular}{|c|c|c|c|}
\hline & & $\begin{array}{c}\text { Influenza } \\
\text { Death Rates }\end{array}$ & $\begin{array}{l}\text { Pneumonia } \\
\text { Death Rates }\end{array}$ \\
\hline Central wards & . & $\begin{array}{l}1.4 \text { in } 1919 \\
2.5 \text { in } 1918\end{array}$ & $\begin{array}{l}1.7 \text { in } 1919 \\
2.6 \text { in } 1918\end{array}$ \\
\hline Middle Ring & . & $\begin{array}{l}1.2 \text { in } 1919 \\
2.7 \text { in } 1918\end{array}$ & $\begin{array}{l}1.1 \text { in } 1919 \\
1.3 \text { in } 1918\end{array}$ \\
\hline Outer Ring & $\ldots$ & $\begin{array}{l}0.9 \text { in } 1919 \\
2.2 \text { in } 1918\end{array}$ & $\begin{array}{l}0.6 \text { in } 1919 \\
0.8 \text { in } 1918\end{array}$ \\
\hline
\end{tabular}

The table shows that the fatality rate in r9r9 was higher among the poorer class areas in the centre than in the wealthier areas on the outskirts. The same discrimination with pneumonia was experienced as in 1918. At the beginning of the pandemics the adults in the younger age-groups were more affected, but that the last epidemic of 1920 reverted to contemporary patterns whereby the greatest mortality rate was among the very young and the very old. Despite all this, however, the infant mortality rate continued to fall in the city.

In the years immediately following, with the exception of 1921 and 1928 , the mortality attributable to influenza was much higher than before 1918. The deaths, in fact, particularly in 1922 and 1924 were high by previous standards and certainly by present ones and it was in the Spring of the latter year that notifications of encephalitis lethargica reached a number never equalled before or since. The period of the maximum incidence coincided with the influenza epidemic of that year.

The figures of influenza for 1928 were the lowest for ten years. But this record of good health, from what has gone before, almost seems to have an ominous ring as in the February of 1929 the epidemic of influenza which had been storming over the country made its appearance in Birmingham. Its onslaught was short but fierce, rising to peak during the first week in March when 575 cases of pneumonia were notified and 402 deaths from influenza and pneumonia were regis-

\section{ENCEPhalitis LethaRgica Notifications} (First notifiable I919)

\begin{tabular}{|c|c|c|c|c|c|}
\hline 1919 & $\cdots$ & $\ldots$ & $\cdots$ & $\ldots$ & I I \\
\hline 1920 & . & $\cdots$ & $\ldots$ & $\ldots$ & 18 \\
\hline 1921 & . & . & . & $\ldots$ & 25 \\
\hline 1922 & $\cdots$ & . & . & . & 12 \\
\hline 1923 & . & . & . & . & 29 \\
\hline I 924 & $\ldots$ & $\ldots$ & $\ldots$ & $\ldots$ & 282 \\
\hline 1925 & .. & . & . & . & 92 \\
\hline 1926 & . & $\cdots$ & $\cdots$ & $\cdots$ & 89 \\
\hline 1927 & $\ldots$ & . & . & . . & 53 \\
\hline 1928 & . & $\cdots$ & . & $\cdots$ & $4 I$ \\
\hline 1929 & . & . & . & . & 27 \\
\hline I930 & . & $\cdots$ & $\cdots$ & . & 10 \\
\hline
\end{tabular}

tered. The death rate reached that week was even higher than any figure reached during the 1918 epidemic. The extraordinary character of the increase in mortality will be more clearly seen in Fig. 2 which shows the weekly number of deaths during the first four months of the year both from all causes and from influenza itself.

The distribution of the mortality over the wards of the City was as follows:

\section{Mortality From Influenza in 1929}

\begin{tabular}{|c|c|c|c|c|}
\hline Central Wards & . & & Average & I.I \\
\hline Middle Ring & & & ", & 1.2 \\
\hline Outer Ring & $\cdots$ & . & ," & 1.0 \\
\hline
\end{tabular}

The heaviest mortality was in Edgbaston, closely $\delta$ followed by Balsall Heath, Handsworth, Lozells and St. Bartholomew's - widely separated wards of a very diverse social character. The lowest rates were in again which are widely separated from each other. Several of the poorest wards in the town had comparatively low rates and it will be noted that the average for the central wards was practically identical with that for the middle and outer rings.

Generally speaking the state of health in Birmingham in the years before any epidemic in the City has not given any indication of what was to follow. The year 1889 , however, was a possible exception as in that year the City was experiencing the end of a long epidemic of scarlet fever. The years previous to the other outbreaks on the other hand were ones with extremely good records from the point of view of health. Nevertheless, when the epidemics came they struck suddenly and widely throughout the City exacting a high toll in deaths and continued to do so for a period of ten years culminating in 1929. During the years from 1889 to 1929 the morbidity rate was never recorded and can only be guessed at, but the loss to the country must have been tremendous. From the records it would appear that the average length of absence from work in 1919 was five days and in the epidemic of 1929 it was ten days for males and I I for females. The loss of productivity was clearly considerable. In the years which followed 1929 there has been a steady downward trend in the deaths from influenza and it has been shown 


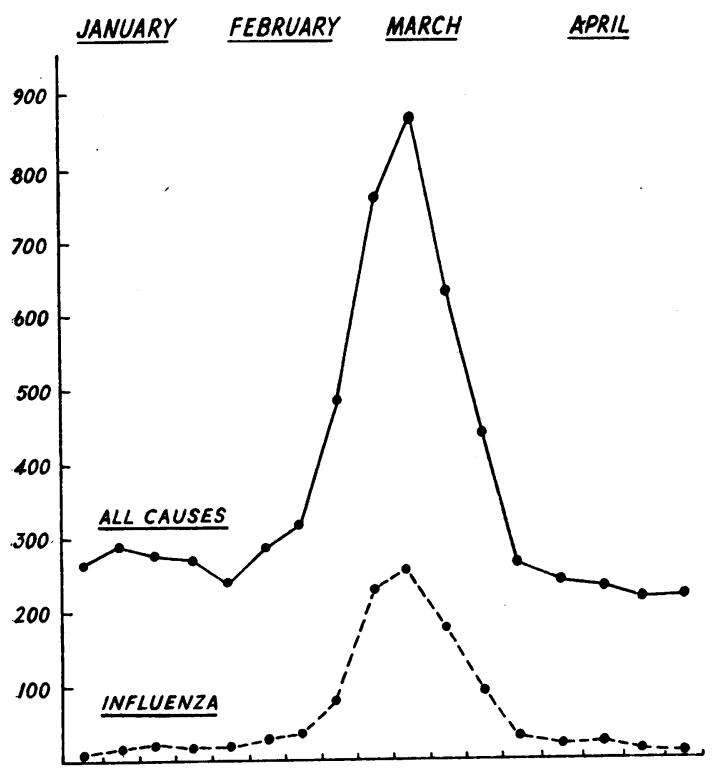

Fig. 2.-Weeekly number of deaths, 1929.

that the trend in Birmingham followed closely that of the country as a whole.

During the war years when influenza was particularly feared there was a happy absence of this disease; with the exception of 1943 it is not referred to in the Annual Reports of the Medical Officer of Health.

In 1943 a wave of influenza beginning late in the November and continuing through December occurred. The epidemic, though widespread, was comparatively mild in type and the period of illness was in general short. However, the disease was prevalent enough to disturb industry and the pressure on the medical service was acute. In fact, in the City, Service medical personnel were made available to help. Therefore, despite its mildness it apparently had a considerable upsetting effect as the Medical Officer of Health in his report of that year refers to the supply of meals from the British Restaurants for home consumption and the provision of aid in the home through the W.V.S. and other voluntary organisations.

\section{Influenza from the More Recent Past to the Present Day}

In this and the previous decade the epidemic incidence of influenza in the country has shown a biennial trend and with the possible exception of r955 the same pattern has been followed in Birmingham. This is seen from the incidence of deaths attributable to this disease and the annual morbidity reports. Since $195^{2}$ general practi- tioners in the City, a few industrial Medica? Officers and Dr. Cohen, Senior School Medicaक Officer, have advised the Department about the incidence of possible epidemics and since the garglings and paired samples of blood have beete taken from any patient suspected of suffering from influenza.

However, it was not until I954 that the Medica市 Officer of Health first reported evidence of viru\$ 'A' and 'B' in the City. Since that date the existance of ' $\mathrm{A}$ ' has been reported every year with. ' $C$ ' occasionally but reference was not again made to 'B' until r96r. Although this scheme of $\operatorname{co} \overrightarrow{\bar{\omega}}$ operation existed in 1952 it was not very activel carried out, according to the Director of the Birmingham Public Health Laboratory Service 3 . but the scheme was extended in 1956 to include sifu members of the Midland Faculty of the College of General Practitioners. This is mentioned now because it has some relevance to a later epidemic?

The year I95 I was one of comparatively higk mortality; the outbreak began at the end of the previous year and reached its height in the first quarter of $195 \mathrm{I}$. The death rate was heaviesh among the aged, although Birmingham was les $\overrightarrow{8}$ seriously affected than other large towns with the exception of London.

Since 1950, the most useful source of infornte tion has been the Ministry of National Insurawe who have supplied the Department with inform tion concerning sickness benefit claims. Although the illness experienced in the epidemic of $195 \mathrm{I}$ was on the whole mild, and Birmingham was less badly affected than the rest of the country, Fig. 3 gives an indication of the impact industrially of this outbreak, despite its mildness. In fact, one in I in Birmingham received benefit at one time and there were $3,107,269$ new claims for benefit from. 19.12.50 to $6.3 .5 \mathrm{I}$ throughout the country. This in fact, was much more than double the figure fort. the previous year.

Although in 1953 an epidemic of influenza has spread over the whole of Europe and the north and south of England the Medical Officer of Health records in his Annual Report for that year thae there was only one case in Birmingham in which the laboratory could partially confirm a diagnosisof influenza. This was a boy, aged 12 years o whose serum showed a rising titre of complemen fixation in regard to Virus 'A'. At the same time he mentions a great deal of illness in the City which he attributed not to influenza but severe colds? This singular assumption obviously based on the lack of virological evidence seems unreasonable especially in face of the already recorded fact that the 'spotting service' was operating extremelyo inadequately, indeed the laboratory service in the City has no records in this respect for that year $\frac{?}{\mathrm{D}}$ 


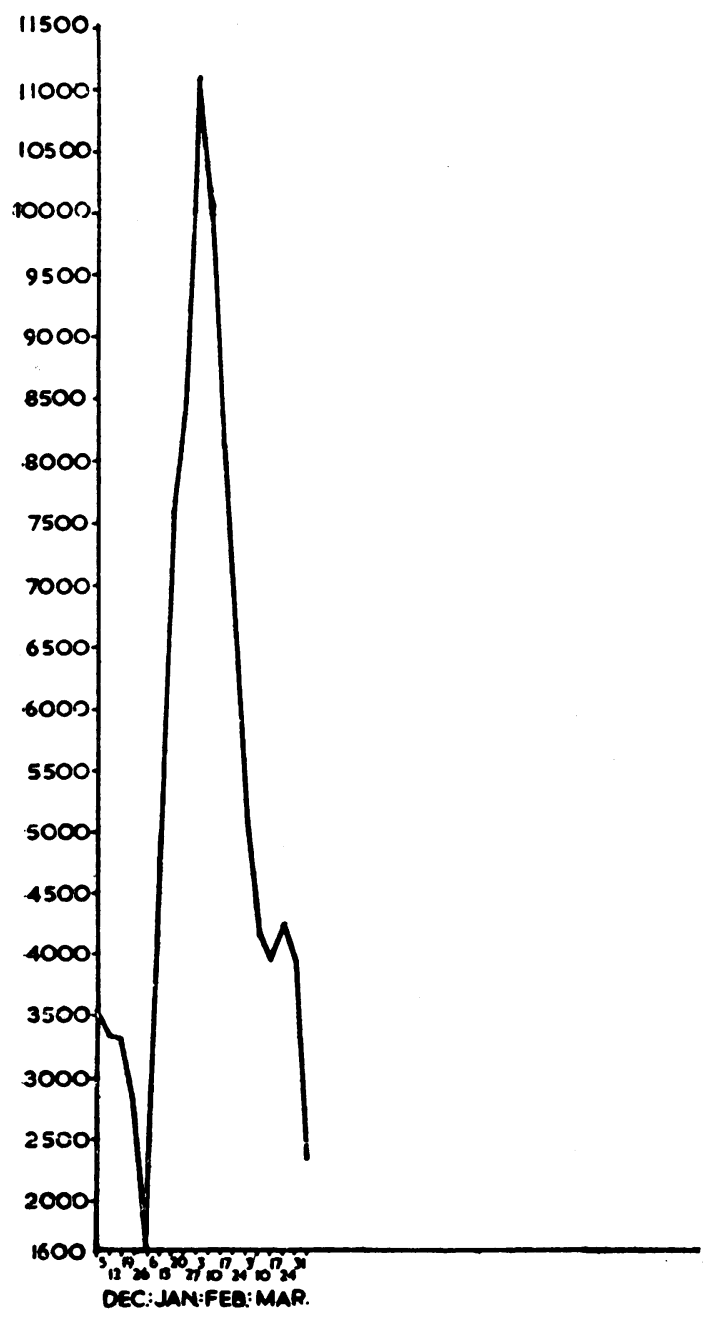

Fig. 3.-National Insurance claims for benefit, December 1950 to March I95I.

Furthermore, the recorded mortality from influenza in Birmingham shows a similar pattern to the country as a whole, while the substantial increase in claims for National Insurance coincide in point of time with the existence of the epidemic in other parts of the country. Despite this absence of virological evidence it seems more reasonable to assume that Birmingham, in fact, shared the experience of the country as a whole.

The most recent extensive epidemic, of course, occurred in 1957 and departed from the accustomed pattern of influenza in that its incidence was usually low in the first and second quarters, but unusually high in the third and fourth quarters through the country. In Birmingham evidence of the disease had occurred in the early part of the year, but it was not until July that reports were received from general practitioners, the Senior School Medical Officer and industrial medical officers, that a considerable number were affected by an influenza-like illness.

In the epidemic that followed school children were particularly heavily hit and absences of up to $60 \%$ were reported. The outbreak seemed to have begun in the south-west area of the City and spread some seven days later in the north-west. It reached the congested central areas last where it spread with great rapidity. At one time 49,352 children were away from primary and secondary modern schools out of 157,000 children-fortunately, only five deaths were attributed to influenza during this period. Considering the number of working mothers in Birmingham the loss to industry by the need for many of them to remain at home during this time must have been enormous. The sickness rate amongst the other members of the working population can be seen from the unseasonal increase in the sickness benefit claims seen in the graph (Fig. 4).

No subsequent epidemic in the City has been as extensive as this one, although the one in 1959 had a heavier death rate and with 195 I shares the highest mortality of recent times. Also in comparison to experience in the country in general, virus ' $B$ ', said to have preceded the appearance of virus ' $A$ ' which was responsible for the major outbreak, was not isolated in Birmingham.

\section{Conclusions}

Influenza in Birmingham, as in the country as a whole, has been responsible for many deaths in the last 70 years. Some of its sequelæ have added to these deaths or condemned its victims to particularly wretched ineffectual lives. In addition, it has caused widespread dislocation to industry and commerce, while the children in the schools have not escaped. Other effects it may have are not clear as figures are not available, but depressive psychosis following influenza is a commonly associated clinical phenomenon and one is left anxious about any teratogenic effect it may have, particularly in the early weeks of pregnancy or its abortifacient action. The recent publication of the Follow-Up Study by Coffey and Jessop (1963) does nothing to allay this anxiety as they point out that the proportion of children with an encephaly born to mothers infected with influenza in the first trimester is ten times that of children born to mothers infected in the third. From Birmingham figures it would appear that the still-birth rate is uninfluenced by outbreaks of influenza, although unfortunately it was not possible to obtain detailed information concerning this, but it is something which will be pursued as it is 


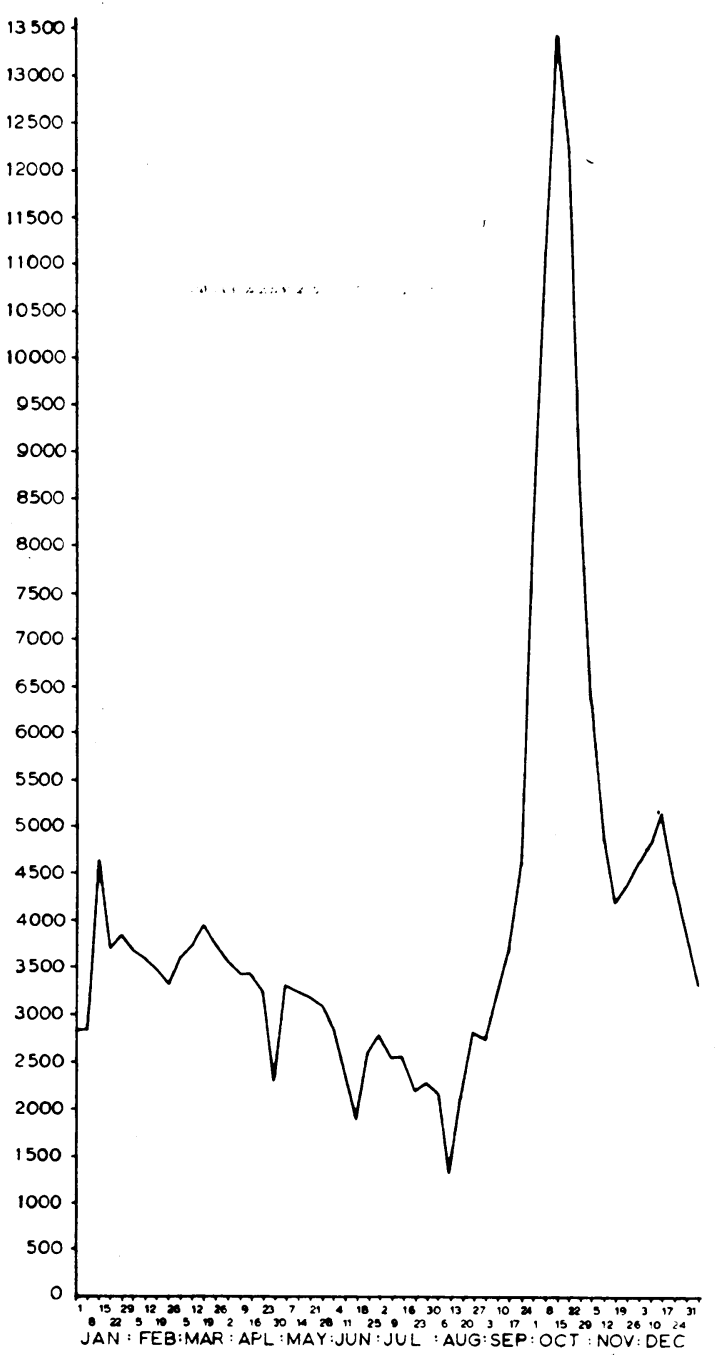

Fig. 4.-National Insurance claims for benefit 1957.

felt that these figures might contain some very useful information.

In addition to the mortality and morbidity caused by influenza, it imposes a tremendous burden, not only on the country as a whole, but on the medical and other ancillary services in particular. Annual Reports repeatedly comment on the strain imposed on the medical services during times of epidemics. Other related services are also in demand followed later by increased applications for convalescence.

In looking back over the years of the last and present century one is left with certain impressions which leave one anxious about a disease which has had such dramatic effects and with a certain feeling of insecurity about the future.

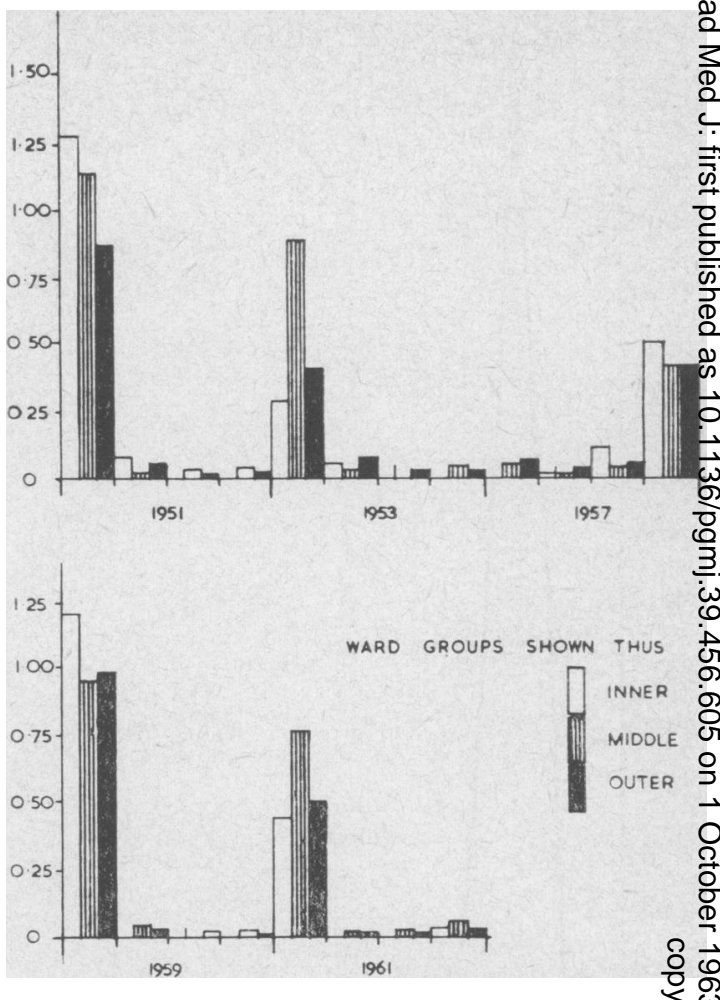

FIG. 5.-Influenza mortality in certain high incideñce years $195 \mathrm{I}-6 \mathrm{I}$. Death rates shown in each quarter and distribution among inner, middle and oute rings of city wards.

While it is true that the World Health Organizae tion and the Ministry of Health provide the Health Department with up-to-date informatio $\mathbb{B}$ concerning the state of influenza throughout the world and in the United Kingdom, there appear to be certain factors of which we are yet unaware which predispose to the appearance or otherwise of an epidemic in any given area.

Certainly the failure of some epidemics to react or spread in this country bear this out and als@ support the suggestion of Magrassi (W.H.O. Monograph, 1954) that 'migration of an individua carrier of infection into new groups of population is insufficient to give rise to influenza'.

Furthermore there is no reason to suppose that influenza in its epidemic form could not originate in this area; experience has shown that if it did the some time could elapse before this was noticed. Indeed, history has shown that even in the face extensive epidemics in this country and elsewhere the occurrence of influenza has passed unrecorded locally. It would appear that there is a primat facie case for improving diagnostic methods?

This is obviously of particular importance in of disease where the causal organism is characterize 
by its ability to appear in a multitude of different strains. Existing vaccines can only afford protection against known strains and even then for a comparatively short period at best, while offering none against any new ones which may appear.

Some comfort can be gained from the decreasing trend in the mortality rate, although the declining mortality attributed directly to influenza may be due to more precise diagnosis of the actual cause of death. However, it seems reasonable to wonder whether this will continue or whether it has reached its lowest level. Perhaps the slight rise recorded in 1959 may indicate an unpleasant answer.

Certainly, there is no ground for complacency with regard to this disease particularly in a large overcrowded cosmopolitan City such as this.

Virological evidence exists of its presence here almost every year in the last decade and research must continue with the object of providing knowledge and preventive measures so that the appearance of this disease is something for which, unlike the last century, we are always effectively prepared.

\section{REFERENCES}

Annual Reports of the Medical Officers of Health of Birmingham (i890): Birmingham: Public Health Department.

Coffey, V., and Jessop, W. J. E. (1963): Maternal Influenza and Congenital Deformities, Lancet, i, 201.

Creighton, C. (1894): 'History of Epidemics', Vol. 2. Cambridge: The University Press.

Ministry OF Health (1920): Annual Reports of the Chief Medical Oficers. London: H.M.S.O.

(1960): The Influenza Epidemic in England and Wales, 1957-58 (Reports on Public Health and Medical Subjects No. 100). London: H.M.S.O.

(1920): Report on the Pandemic of Influenza, 1918-r9 (Report on Public Health No. 4).

Medical Research Council Committee (1959): Reports by the Joint Working Party on Influenza and Other Respiratory Virus Vaccines and of the Research Committee of the British Tuberculosis Association. Field Trial of Influenza Virus Vaccine in Patients with Chronic Bronchitis During the Winter 1957-58, Brit. med. $\mathcal{Y}$., ii, 905,

StUART-HarRis, C. H. (1947): Prevention of Acute Respiratory Disease with Special Reference to Influenza, Lancet i, 201 .

ANDrewes, C. H., and Smith, W. (1938): A Study of Epidemic Influenza with Special Reference to the r936-37 Epidemic, Spec. Rep. Ser. med. Res. Coun. (Lond.), No. 228.

World Health Organization (I954): Influenza: A Review of Current Research. Monograph No. 20. 